\title{
APLICAÇÃO DA FERRAMENTA QFD NA INDÚSTRIA DE ARTEFATOS DE CONCRETO
}

\section{Lucas Vinícius Reis}

Graduação em Engenharia de Produção Universidade de Santa Cruz do Sul - UNISC lucasviniciusreis@gmail.com

\section{Matheus André Mallmann}

Graduação em Engenharia de Produção Universidade de Santa Cruz do Sul - UNISC matheus.a.mallmann@hotmail.com

\section{Ana Claudia Lopes de Carvalho}

Graduação em Engenharia de Produção Universidade de Santa Cruz do Sul - UNISC anaclaudiadecarvalho@icloud.com

\author{
Letícia Diesel \\ Mestre em Engenharia de Produção - \\ Universidade Federal de Santa Maria, UFSM, \\ Brasil. \\ 1diesel@unisc.br \\ André Luiz Emmel Silva \\ Mestrado em Tecnologia Ambiental - \\ Universidade de Santa Cruz do Sul, UNISC, \\ Brasil. \\ andresilva@unisc.br
}

\begin{abstract}
RESUMO
Visto que a satisfação do cliente é a chave para o sucesso, é necessário ficar atendo as suas necessidades, para poder oferecer um produto que possa supri-las. As necessidades do cliente podem ser traduzidas em forma de requisitos de qualidade, que devem estar claros para a organização, possibilitando a tomada de ações no sentido de corrigir possíveis desvios. Baseado neste preceito, o QFD (Quality Function Deployment) encontra cada vez mais espaço na indústria, à medida que se observa o acirramento da competitividade entre as empresas e o aumento do nível de exigência dos consumidores. O objetivo deste trabalho é propor a implantação da ferramenta QFD em uma empresa produtora de artefatos de concreto, situada na região do Vale do Rio Pardo no estado do Rio Grande do Sul, promovendo um aumento nos diversos aspectos de qualidade de seu principal produto, postes de concreto para utilização em redes de transmissão de energia. Para elaboração da matriz QFD, utilizou-se um questionário estruturado aplicado aos principais clientes, com perguntas fechadas de múltipla escolha sendo que ao final do estudo os atributos identificados como de maior relevância para a tomada de ações de melhoria na qualidade foram a resistência do concreto e a armadura.
\end{abstract}

Palavras-chave: QFD; Artefatos de concreto; Qualidade; Ferramentas da qualidade. 


\begin{abstract}
Since customer satisfaction is the key to success, you must be attend to your needs, to offer a product that can meet them. Customer needs can be translated in the form of quality requirements that must be clear to the organization allowing taking actions to correct possible deviations. Based on this precept, QFD (Quality Function Deployment) is more space in the industry, as we observe the intensification of competition between companies and the increase in the level of consumer demand. The objective of this study is to propose the implementation of QFD tool in a company producing concrete artifacts, located in the region of Vale do Rio Pardo in the state of Rio Grande do Sul, promoting an increase in the various aspects of quality of its main product, poles concrete for use in power transmission networks. For preparation of the QFD matrix, we used a structured questionnaire applied to major customers with closed multiple-choice questions and at the end of the study, the attributes identified as most relevant for taking actions to improve the quality were the strength of concrete and armor.
\end{abstract}

Keywords: QFD; Concrete artifacts; Quality; Quality tools.

\title{
1. INTRODUÇÃO
}

O Brasil está passando por um momento econômico no qual há uma desaceleração do consumo, acarretando em uma retração da indústria. Para a sobrevivência das empresas, o desenvolvimento de produtos focados nos requisitos dos clientes tem se tornado de suma importância, visto que a vantagem competitiva é obtida pelo competidor que, com maior precisão, satisfaz seus clientes. Deste modo os produtos devem possuir características e atributos que adicionem valor ao cliente, intensificando sua satisfação para obter sua preferência e fidelidade.

Como a qualidade está associada à percepção do consumidor, é extremamente importante saber em que aspectos um produto é melhor ou pior que os outros ofertados no mercado. Diante disto o Desdobramento da Função Qualidade (QFD, do inglês Quality Function Deployment) apresenta-se como uma ferramenta fundamental (LOOS e MIGUEL, 2014). O QFD permite identificar os requerimentos almejados pelo cliente e seus respectivos graus de importância (SCHELLER e MIGUEL, 2012). Desta forma auxilia na obtenção da vantagem competitiva, incorporando e assegurando qualidade ao produto durante a fase de produção e também de utilização pelo usuário final.

Este método tornou-se bastante utilizado na tomada de decisão de empresas e os estudos sobre as possibilidades de sua aplicação estão se difundindo no meio acadêmico. Existem pesquisas que buscam identificar onde o QFD está sendo aplicado, quem está aplicando e de que modo, as áreas funcionais envolvidas, os tipos de produto e os resultados obtidos (CHENG, 2003). Estes estudos servem de base para que os colaboradores de empresas interessadas no método possam desenvolver a ferramenta de acordo com as características da companhia na qual estão inseridos. O objetivo deste trabalho é estabelecer os requisitos dos clientes de uma empresa produtora de artefatos de concreto, e realizar uma análise por meio da utilização da metodologia QFD para identificar os pontos chaves para aplicação de esforços na melhoria da qualidade do produto ofertado ao consumidor, de forma a atender suas expectativas, tornando a empresa mais competitiva. 


\section{FUNDAMENTAÇÃO TEÓRICA}

Neste capítulo será apresentada uma breve discussão acerca dos conceitos da indústria de artefatos de concreto e da ferramenta QFD.

\subsection{Indústria de artefatos de concreto}

O macro setor da construção é composto por indústrias de diversos seguimentos, dentre elas as fábricas de artefatos de concreto. Os principais insumos utilizados nos processos produtivos deste tipo de empresa são: cimento, aço, água, areia e brita. No Brasil a indústria de artefatos de concreto está distribuída em 8 tipos fundamentais: Lajes pré-fabricadas, 25,1\%; Produtos de fibrocimento, 23,3\%; Argamassas industrializadas, 17,4\%; Construção industrializada, 14,9\%; Blocos de concreto, 13,4\%; Postes de concreto, 3\%; Tubos de concreto, 1,7\%; e Elementos arquitetônicos, 1,2\% (FIEMG, 2009).

Em 2013 o setor representava cerca 7,8 mil empresas ativas no Brasil, sendo responsáveis pela geração de 126 mil empregos (diretos e indiretos). Em 2013, o setor apresentou um faturamento de R\$ 9,67 bilhões, o que representou um crescimento de $2,8 \%$ na arrecadação em comparação com o ano anterior (SINAPROCIM, 2014). Na figura 1 pode-se visualizar um gráfico com a tendência de crescimento na produção anual (toneladas) de artefatos de concreto, no período de 2008 a 2014.

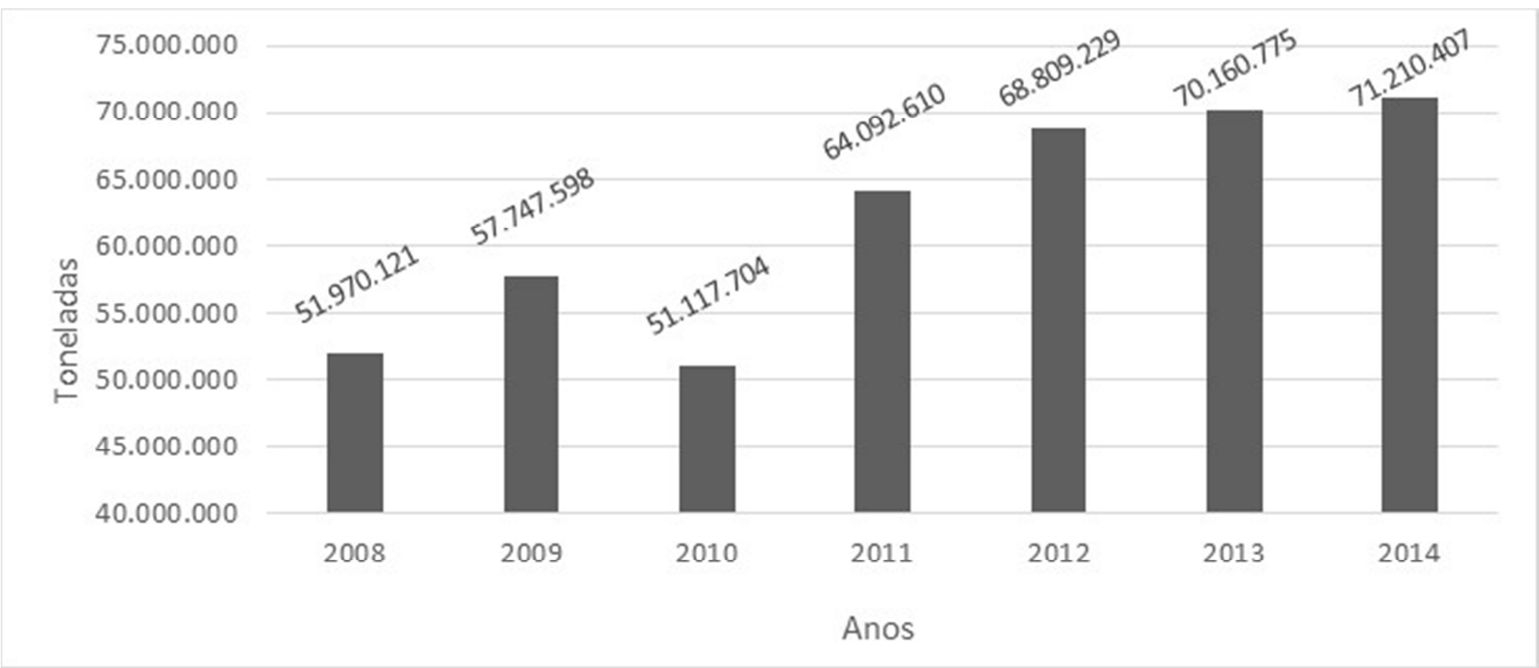

Figura 1: Produção Anual de Artefatos de Concreto no Brasil Fonte: Adaptado de H-ZEN(2015).

A figura 1 expõe a produção anual do setor em um cenário de 7 anos. Onde este apresentou crescimento do primeiro para o segundo ano, mas que apresentou um ano de baixa produção em 2010, contudo retornou a sua tendência de desenvolvimento no ano seguinte, com um incremento de mais de $25 \%$ na sua produção anual. Os anos subsequentes também apresentaram um acréscimo de produção

\subsection{Desdobramento da função qualidade}

Inúmeras ferramentas são desenvolvidas para aprimorar a qualidade de produtos e serviços de forma a atender as expectativas dos consumidores, dentre elas, encontra-se o QFD. Segundo Pianna e Reis (2015), é a satisfação dos clientes que demonstra a qualidade dos serviços prestados. Atualmente, não se pode mais considerar a gestão da qualidade como um diferencial competitivo de uma companhia, visto que esta tornou-se um fator determinante para a manutenção das empresas em um mercado com consumidores que demandam produtos e serviços cada vez mais eficientes (MENDONÇA, PINHEIRO e HORA, 2010). 
A ferramenta QFD foi desenvolvido pelos professores Akao e Mizuno no final da década de 60 e início da década de 70. É um sistema que possibilita traduzir as exigências do cliente em funções de qualidade do projeto, produto ou serviço (AKAO, 1990; JÚNIOR, 2012; MIGUEL, 2006). Essa abordagem possibilita à empresa agir de forma proativa na resolução de problemas relativos à qualidade, ao invés de adotar uma postura reativa perante as reclamações dos clientes (BÜYÜKÖZKAN e ÇIFÇI, 2013; KARSAK e DURSUN, 2013).

O QFD é um método capaz de otimizar as características do produto e a alocação de recursos em pontos estratégicos (PRASZKIEWICZ, 2013). É um instrumento gerencial que auxilia na garantia da qualidade durante o desenvolvimento de um produto e pode ser conceituado como uma forma de traduzir as reais necessidades de clientes em informações de projeto e de explicitar ordenadamente o trabalho relacionado com a obtenção dessa qualidade (CHENG e MELO, 2010).

A partir de necessidades encontradas através de entrevistas com clientes e de características de qualidades do produto definidas internamente, a empresa pode fazer o cruzamento destas informações dentro da primeira matriz do QFD, conhecida como casa da qualidade. Esta pode ser considerada o núcleo do QFD, onde os requisitos do cliente são convertidos em características funcionais dos produtos de forma eficiente, usando a matriz de relacionamento da casa da qualidade (DU, et al. 2013). Em seguida é feito o desdobramento dos requisitos de projeto em características do produto ou serviço. Estes são desdobrados em especificações de processos. Por último é feito o desdobramento das especificações de processo em requisitos de produção, compondo assim o conjunto de matrizes do QFD das quatro fases, o mais conhecido modelo de QFD (FNQ, 2008).

Existe ainda o modelo desenvolvido por Don Clausing, denominado QFD estendido que possui as mesmas quatro fases do modelo anterior, porém em sua fase de projeto é desdobrado em três matrizes: Projeto dos sistemas, projeto dos subsistemas e projeto dos componentes (MIGUEL, 2008). E o QFD das quatro ênfases, chamado assim, porque é desdobrado nas ênfases qualidade, tecnologia, custo e confiabilidade. Este modelo possui dois subdesdobramentos: Desdobramento da função qualidade no sentido restrito (QFDr) e Desdobramento da qualidade (QD). O primeiro consiste no desdobramento do trabalho e o segundo no desdobramento do produto (CHENG, 1995 Apud PEIXOTO E CARPINETTI, 1998).

Originalmente o QFD foi concebido para auxiliar as organizações no desenvolvimento de produtos, porém atualmente é aplicado em cadeias de suprimento, qualidade na prestação de serviços, aperfeiçoamento de produtos, gestão de conhecimento, avaliação de ensino dentre outros. Embora tenha uma ampla aplicação, seu emprego dentro das pesquisas no Brasil ainda é fortemente utilizado no auxílio ao desenvolvimento de produto. As publicações têm o predomínio do estudo de caso, focado nas indústrias de transformação (LOOS e MIGUEL, 2014). A exemplo dos recentes trabalhos de Marx, Echeveste e Paula (2011), SELLITTO e UNTERLEIDER (2012), PINTO e FONTENELLE (2013).

O QFD traduz os desejos dos clientes em requisitos técnicos, que posteriormente são desdobrados em requisitos dos componentes, requisitos de processo e requisitos de produção. Para poder constituir essas relações, o QFD geralmente requer quatro matrizes (Figura 2) sendo que cada uma corresponde a uma etapa do ciclo de desenvolvimento do produto. A matriz de planejamento de produto tem como finalidade traduzir as necessidades dos consumidores em atributos técnicos; a matriz de desdobramento das partes traduz atributos técnicos em características do produto; a matriz de planejamento do processo traduz características do produto em requisitos de processo; a matriz de planejamento da produção traduz requisitos de processo em requisitos de produção (KARSAK e DURSUN, 2013).

Persp. Online: exatas \& eng., Campos dos Goytacazes, 17 (07) 1-11 - 2017

seer.perspectivasonline.com.br 


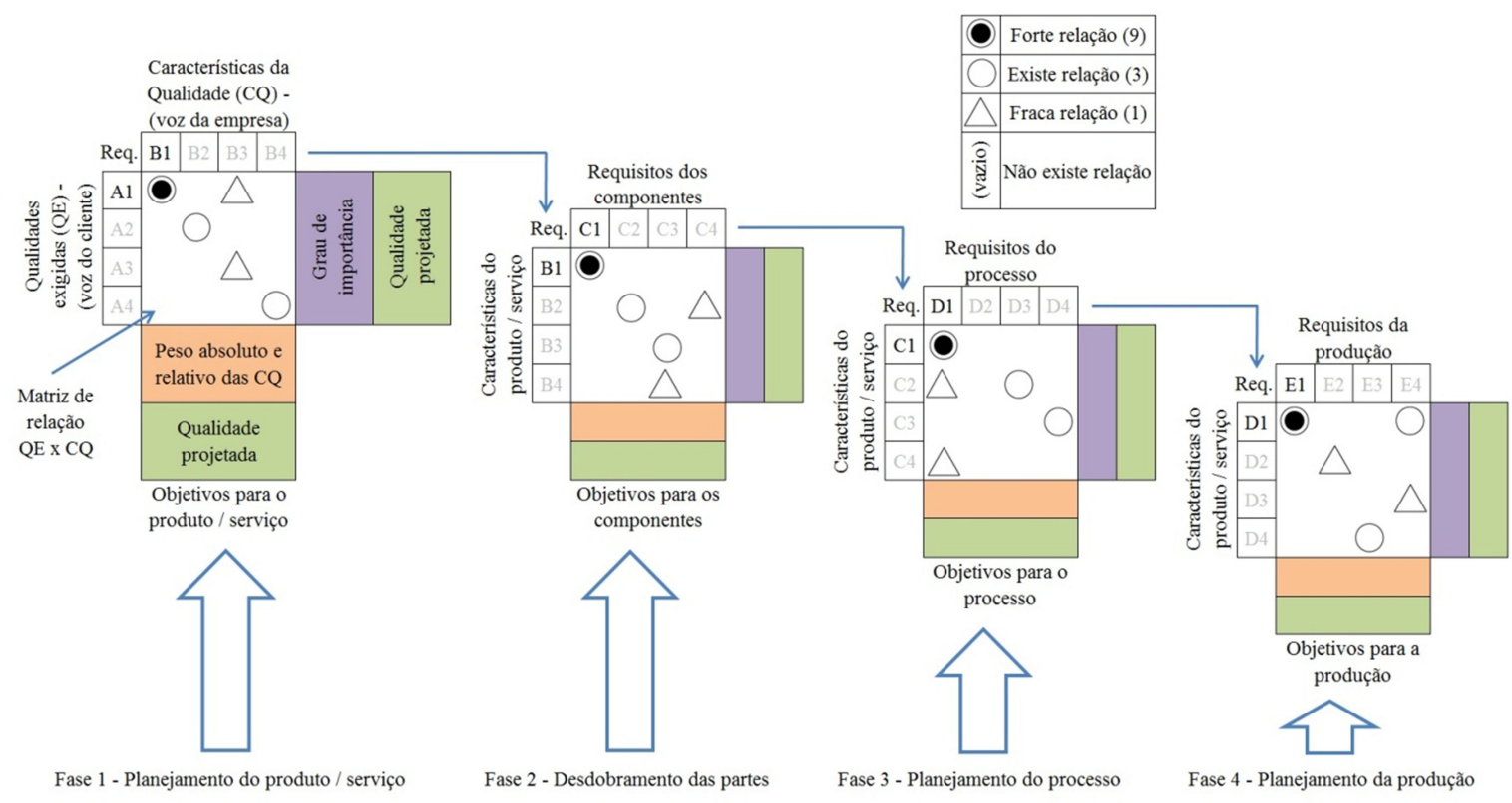

Figura 2: Matrizes de desdobramento do QFD

Fonte: Adaptado de MIGUEL, 2008.

A primeira matriz do QFD é também conhecida como a casa da qualidade e pode ser considerada a parte vital deste método, pois permite uma rápida comparação visual do cruzamento das necessidades dos clientes com o que a empresa pode oferecer (BUYUKOZKAN e ÇIFCI, 2013). É um mapa conceitual que fornece os meios para o planejamento e contém sete elementos (KARSAK e DURSUN, 2013), sendo que muitas vezes a aplicação do QFD baseia-se unicamente nesta matriz (figura 3). 


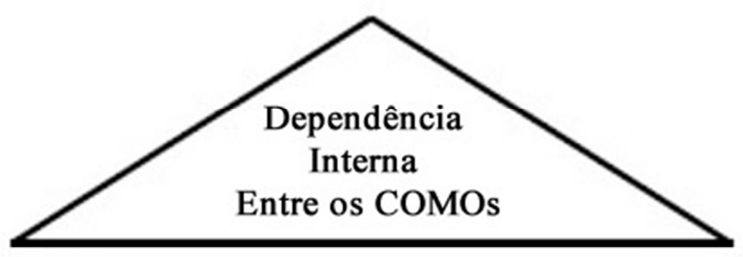

Atributos Técnicos

"COMO se pretende fazer"
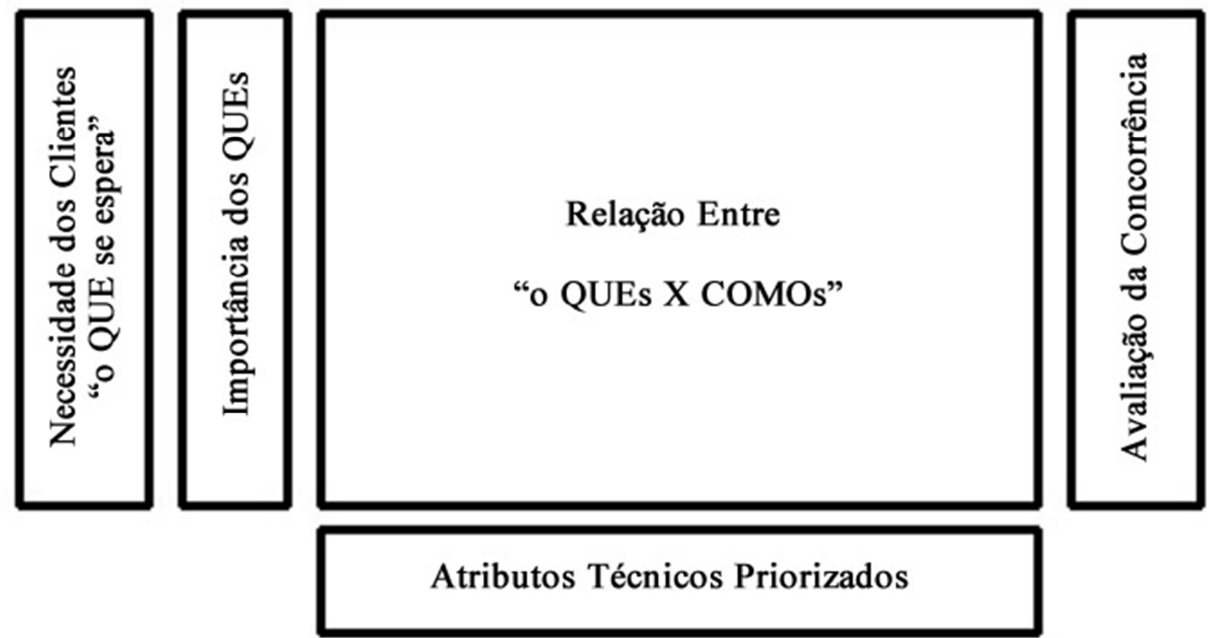

Figura 3: Casa da qualidade e seus elementos

Fonte: adaptado de KARSAK e DURSUN, 2013.

Independente do modelo de QFD adotado, sua aplicação gera inúmeras vantagens para as organizações. Kamvysi et al. (2014) comentam que este método é capaz de sistematizar a comunicação, reduzir custos, aumentar as receitas, reduz o tempo de desenvolvimento de novos produtos e serviços e facilita a coordenação de decisões orientadas ao cliente.

\section{METODOLOGIA}

O presente trabalho é classificado quanto aos seus objetivos como exploratório, pelo fato de propiciar maior familiaridade com o problema (YIN, 2015). Enquanto à forma de abordagem é quantitativa, uma vez que traduz em números opiniões e informações classificadas e analisadas. Do ponto de vista do procedimento de pesquisa, enquadra-se como estudo de caso, sendo que este método se utiliza de planejamento, técnicas de coleta e análise de dados, sendo definido como uma investigação empírica que apura de forma profunda um fenômeno contemporâneo inserido no seu contexto (YIN, 2015).

Para a realização da pesquisa utilizou-se uma amostra não probabilística (não casual), onde a escolha dos elementos não é feita aleatoriamente. Sendo do tipo intencional, a amostra é escolhida propositalmente pelo pesquisador. Já o método de coleta de dados empregado foi o questionário estruturado, validado com especialistas da empresa. A fim de obter o embasamento teórico necessário para a realização deste estudo, realizou-se a fundamentação teórica, onde foram buscados livros e artigos de autores identificados como relevantes dentro do assunto abordado. 
O estudo foi aplicado em uma empresa produtora de postes de concreto, situada na região do Vale do Rio Pardo, interior do estado do Rio Grande do Sul, Brasil. Além desta unidade, a companhia possui outras sete filiais no país e atua em diversos outros países da América Latina e em Angola. Possui uma área fabril de $3800 \mathrm{~m}^{2}$ construídos em um terreno de $80100 \mathrm{~m}^{2}$ e 40 funcionários trabalhando em turno único. Para a identificação das necessidades do consumidor, foram aplicados questionários a uma amostra de duas empresas que são as principais clientes da empresa estudada. Os questionários foram elaborados com cuidado para apresentar uma linguagem clara e de fácil entendimento. Foram utilizadas perguntas fechadas de múltipla escolha com escala likert. Após a coleta dos dados procedeu-se com a tabulação dos mesmos, em seguida realizou-se a montagem e análise da matriz QFD, conforme metodologia apresentada na figura 4.

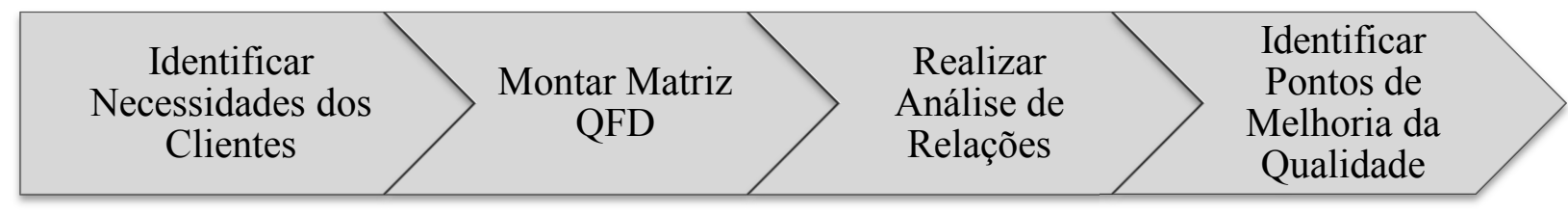

Figura 4: Metodologia QFD aplicada

Fonte: Elaborado pelos autores.

\section{RESULTADOS E DISCUSSÃO}

Por meio dos questionários foram obtidas as seguintes necessidades dos clientes: Atende Flexões, Dimensional, Durabilidade, Identificação, Preço, Recobrimento e Segurança. Posteriormente formam atribuídos pelos clientes o grau de importância através de uma escala Likert de 5 pontos (variando de 1 a 5, sendo 1- Sem Importância, 2- Pouco Importante, 3- Importante, 4- Muito Importante, 5- Extremamente Importante). Na tabela 1 encontrasse o resultado desta avaliação, sendo o valor da segunda coluna, o grau médio do questionário aplicado a um representante de cada empresa cliente.

Tabela 1: Necessidades dos clientes X grau de importância

\begin{tabular}{cc}
\hline Necessidades dos Clientes & Grau de Importância \\
\hline Atende Flexões & 5 \\
Dimensional & 5 \\
Durabilidade & 5 \\
Identificação & 4 \\
Preço & 5 \\
Recobrimento & 5 \\
Segurança & 5 \\
\hline
\end{tabular}

Em seguida procedeu-se com a elaboração da qualidade planejada, que compreende uma avaliação feita pelos clientes, sobre o desempenho do produto da empresa e dos produtos concorrentes (MIGUEL, 2008). Também se utilizou de uma escala Likert de 5 pontos (sendo 1- Péssimo, 2- Ruim, 3- Bom, 4- Muito Bom, 5 -Excelente). O resultado médio desta avaliação encontrasse na tabela 2. 
Tabela 2: Avaliação de desempenho do produto

\begin{tabular}{|c|c|c|c|c|c|c|c|c|}
\hline \multirow{3}{*}{ Atende Flexões } & Empresa & 5 & \multirow{3}{*}{ Identificação } & Empresa & 4 & \multirow{3}{*}{ Recobrimento } & Empresa & 5 \\
\hline & Concor. X & 5 & & Concor. X & 4 & & Concor. X & 5 \\
\hline & Concor. Y & 5 & & Concor. Y & 3 & & Concor. Y & 5 \\
\hline \multirow{3}{*}{ Dimensional } & Empresa & 5 & \multirow{3}{*}{ Preço } & Empresa & 4 & \multirow{3}{*}{ Segurança } & Empresa & 5 \\
\hline & Concor. X & 5 & & Concor. X & 4 & & Concor. X & 5 \\
\hline & Concor. Y & 5 & & Concor. Y & 4 & & Concor. Y & 5 \\
\hline \multirow{3}{*}{ Durabilidade } & Empresa & 4 & & & & & & \\
\hline & Concor. X & 4 & & & & & & \\
\hline & Concor. Y & 4 & & & & & & \\
\hline
\end{tabular}

A partir deste comparativo a empresa estipulou sua qualidade planejada (também em uma escala likert de 5 pontos): Atende Flexões, 5; Dimensional, 5 ; Durabilidade, 5; Identificação, 4; Preço, 4; Recobrimento, 5; Segurança, 5;

Com base nesses dados determinou-se a taxa de melhoria e o argumento de vendas (Figura 4). A taxa de melhoria é obtida pela divisão da qualidade planejada pelo desempenho atual do produto (MIGUEL, 2008). Já o valor do argumento de vendas advém de uma escala ponderada de quão estratégica é a qualidade exigida, onde 1 representa uma qualidade "óbvia"; 1,2 uma qualidade "comum" e 1,5 para uma qualidade "atrativa" (MIGUEL, 2008).

Por seguinte, calculou-se o peso absoluto e o peso relativo de cada requisito do consumidor (Figura 5). Sendo esses valores expressos pela multiplicação do grau de importância pela taxa de melhoria e pelo argumento de vendas (MIGUEL, 2008).

Procedeu-se então com a avaliação das intensidades de relações entre as necessidades dos clientes e os atributos técnicos, através de uma escala: tendo 9 como forte relação; 3 como moderada relação; 1 como fraca relação e 0 como relação inexistente; Finalmente obteve-se o peso absoluto dos atributos técnicos, através do somatório da multiplicação do peso absoluto do requisito do consumidor pela relação de intensidade estabelecida na coluna.

\begin{tabular}{|c|c|c|c|c|c|c|c|c|c|c|c|c|c|c|c|c|}
\hline $\begin{array}{c}\text { Requisitos } \\
\text { do } \\
\begin{array}{c}\text { Cliente (RC) } \\
\text { RC }\end{array}\end{array}$ & 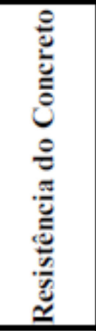 & 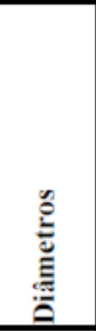 & 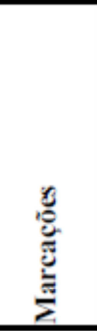 & 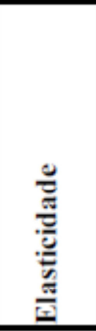 & 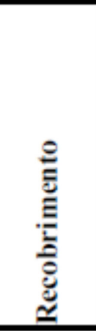 & 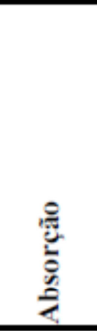 & 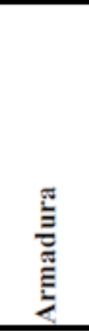 & 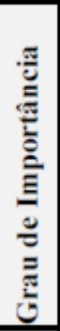 & 苞 & 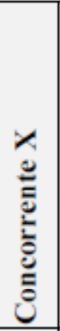 & 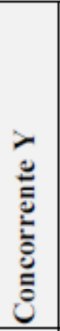 & 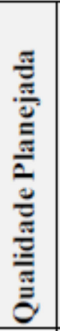 & 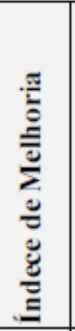 & 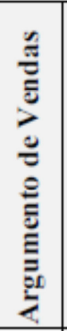 & 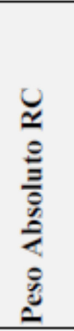 & 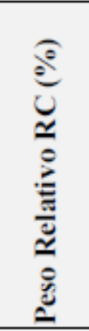 \\
\hline Atende Flexões & 9 & 1 & & 3 & 1 & 3 & 9 & 5 & 5 & 5 & 5 & 5 & 1 & 1,2 & 6,00 & $14,4 \%$ \\
\hline Dimensional & & 9 & & & 3 & & & 5 & 5 & 5 & 5 & 5 & 1 & 1 & 5,00 & $12,0 \%$ \\
\hline Durabilidade & 9 & & & 1 & 3 & 3 & 3 & 5 & 4 & 4 & 4 & 5 & 1,25 & 1 & 6,25 & $15,0 \%$ \\
\hline Identificações & & & 9 & & 3 & 1 & & 4 & 4 & 4 & 3 & 5 & 1,25 & 1 & 5,00 & $12,0 \%$ \\
\hline Preço & 9 & & & 1 & & 1 & 9 & 5 & 4 & 4 & 4 & 5 & 1,25 & 1,5 & 9,38 & $22,5 \%$ \\
\hline Recobrimento & 1 & & & 1 & & & 3 & 5 & 5 & 5 & 5 & 5 & 1 & 1 & 5,00 & $12,0 \%$ \\
\hline Segurança & 3 & & & 3 & & & 3 & 5 & 5 & 5 & 5 & 5 & 1 & 1 & 5,00 & $12,0 \%$ \\
\hline Peso Absoluto AT & 515,62 & 122,52 & 108,11 & 128,83 & 131,53 & 122,82 & 449,55 & \multicolumn{2}{|c|}{1578,98} & & & & & & \multirow[t]{2}{*}{41,63} & \multirow[t]{2}{*}{$100 \%$} \\
\hline Peso Relativo AT (\%) & $32,7 \%$ & $7,8 \%$ & $6,8 \%$ & $8,2 \%$ & $8,3 \%$ & $7,8 \%$ & $28,5 \%$ & \multicolumn{2}{|c|}{$100,0 \%$} & & & & & & & \\
\hline
\end{tabular}

Figura 5: Casa da Qualidade 
Por meio da utilização do QFD foi possível identificar os atributos técnicos que apresentam maior influência na satisfação do cliente. A figura 6 apresenta estes atributos de acordo com seu grau de priorização para o estabelecimento de ações que visem um aumento de qualidade dos produtos fabricados.

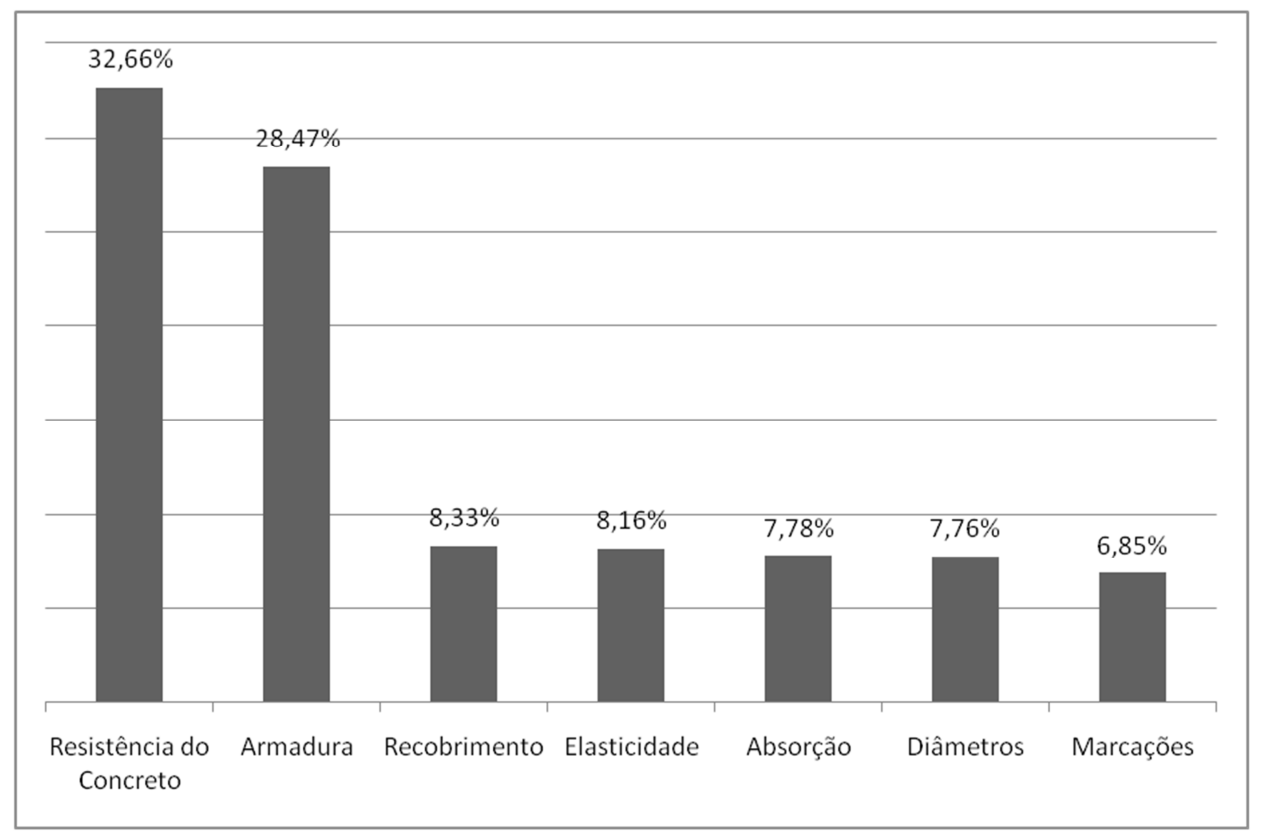

Figura 6: Priorização de ações

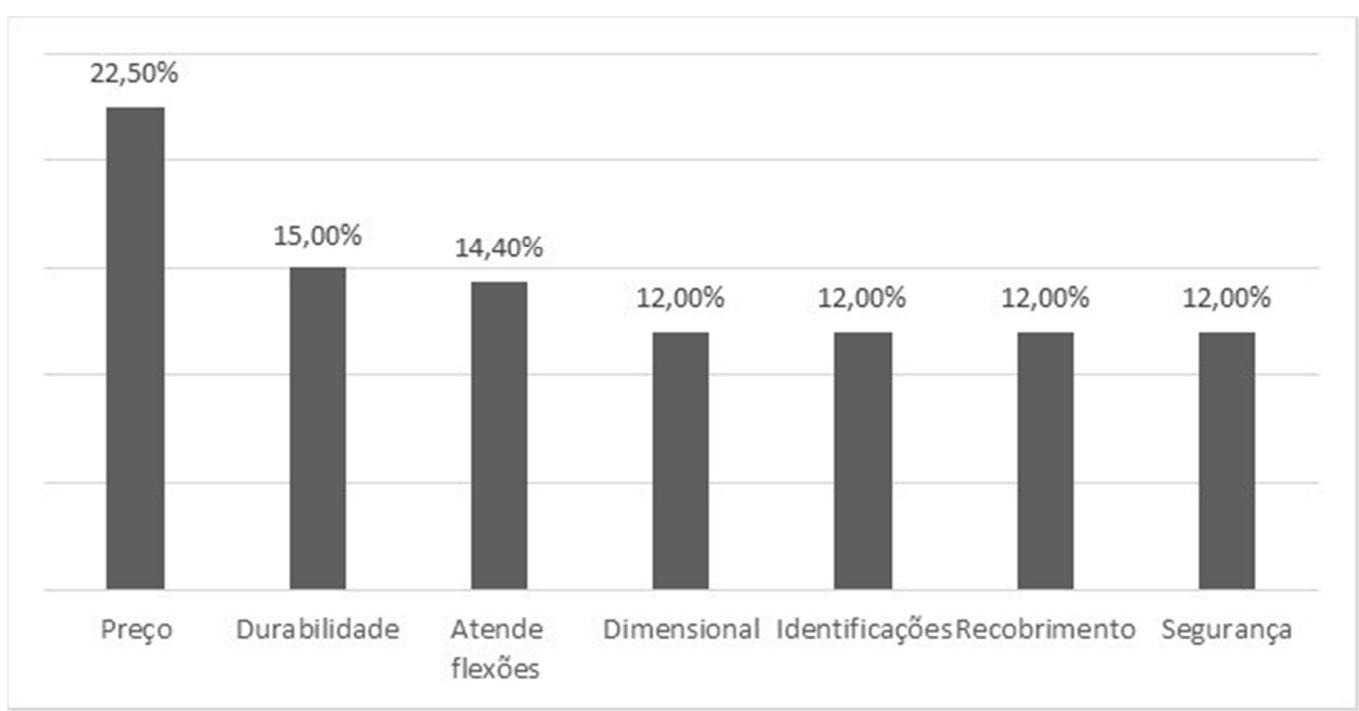

Figura 7: Priorização dos requisitos dos clientes 
Já a figura 7 apresenta a priorização dos requisitos sobre a ótica dos clientes, onde o preço é o item com maior importância para atender a satisfação dos clientes. Realizando um comparativo é possível verificar que os itens resistência do concreto e armadura da figura 6, estão diretamente ligados ao item preço indicado na figura 7 , pois tanto a resistência do concreto quanto a armadura são etapas de alto custo dentro da produção dos postes, o que impacta diretamente no preço do produto oferecido ao cliente.

\section{CONCLUSÕES}

A utilização do QFD permite a definição das características de qualidade de maior relevância para os clientes, possibilitando que o fabricante possa focar seus esforços na melhoria de aspectos realmente importantes, eliminando o processo empírico, muitas vezes adotado pelas empresas, que busca identificar estes aspectos através de percepções internas. A ferramenta QFD possibilitou a identificação dos principais atributos técnicos que os postes de concreto, fabricados pela empresa estudada possui, com base nos requisitos de qualidade apontados pelos seus principais clientes. Através dos cálculos realizados foi possível estabelecer uma ordem de priorização para ações de melhoria contínua.

A resistência do concreto e a armadura são os atributos que apresentaram maior grau de importância, necessitando maior atenção por parte da organização, sendo estes os que mais afetam a satisfação dos seus clientes. Propõem-se como futuros estudos, o estabelecimento de indicadores de desempenho que possam mensurar os resultados das ações de melhoria implantadas a partir das priorizações definidas nesta pesquisa. Também poderiam ser aplicados os demais desdobramentos da casa da qualidade, podendo aumentar ainda mais a eficácia em satisfazer os clientes.

\section{REFERÊNCIAS BIBLIOGRÁFICAS}

AKAO, Y. Quality Function Deployment. Cambridge: Productivity Press, 1990.

BÜYÜKÖZKAN, G. \& ÇIFÇI, G. An integrated QFD framework with multiple formatted and incomplete preferences: A sustainable supply chain application. Applied soft computing. v. 13, n. 9, p. 3931-3941, 2013.

CHENG, L. C. QFD em desenvolvimento de produto: características metodológicas e um guia para intervenção. Produção Online. V. 3, n. 2, 2003.

CHENG, L. C. \& MELO FILHO, L. D. R. QFD: Desdobramento da função qualidade na gestão de desenvolvimento de produtos. 2. ed. São Paulo: Blücher, 2010.

DU, Y.; CAO, H.; CHEN, X. \& WANG, B. Reuse-oriented redesign method of used products based on axiomatic design theory and QFD. Journal of Cleaner Production, v. 39, p. 79-86, 2013.

DURSUN, M. \& KARSAK, E. E. A QFD based fuzzy MCDM approach for supplier selection. Applied Mathematical Modeling, V. 37 p. 5864-5875, 2013.

FIEMG - Federação das Indústrias de Minas Gerais. Guia de Sustentabilidade do Setor de artefatos de cimento. 2009.2 Disponível em: $<$ http://www.fiemg.org.br/admin/BibliotecaDeArquivos/Image.aspx?ImgId=22019\&TabId=3464>. Acesso em: 09 dez. 2015.

FNQ. Cadernos de excelência: Clientes / Fundação Nacional da Qualidade. Série Cadernos de Excelência. n. 3, São Paulo, 2008. 
H-ZEN - Soluções Industriais. Produção de Artefatos de cimento: Por que automatizar? 2015. Disponível em: <http://www.hzen.ind.br/blog/artefatos-de-cimento-por-que-automatizar/>. Acesso em: 11 dez. 2015.

Dias Jr., F. J, Muniz Jr, J., Claro, F. A. E., e Nakano, D. N. (2012). Desdobramento da função qualidade (QFD) no desenvolvimento de projeto de treinamento: estudo exploratório para serviço. Revista Produção Online, v. 12, n. 1, p. 91-118, 2012.

KAMVYSI, K.; GOTZAMANI, K.; ANDRONIKIDIS, A. \& GEORGIOU, A. C. Capturing and prioritizing students' requirements for course design by embedding Fuzzy-AHP and linear programming in QFD. European Journal of Operational Research, V. 237, p. 1083-1094, 2014.

LOOS, M. J. \& MIGUEL, P. A. C. Utilização do QFD no desenvolvimento de novos produtos: uma análise das publicações em periódicos nacionais. Produto \& Produção (Online), v. 15, p. 17-31, 2014.

MARX, A. M.; ECHEVESTE, M. E. S. \& PAULA, I. C. Desdobramento da função qualidade aplicado ao projeto de um detergente sustentável. Produção, v. 21, p. 724-741, 2011.

MENDONÇA, M. D. S.; PINHEIRO, S. S.; Da HORA, H. R. M., \& COSTA, H. G. Análise da eficácia da implantação do programa 5s: um estudo de casos em uma indústria moveleira. Perspectivas Online, v. 4, n. 13, p. 20-35, 2010.

MIGUEL, P. A. C. \& CARNEVALLI, J. A. Aplicações não-convencionais do desdobramento da função qualidade. São Paulo: Artliber, 2006.

MIGUEL, P. A. C. Implementação do QFD para o Desenvolvimento de Novos Produtos. São Paulo: Atlas S.A., 2008.

PIANNA, L. M. \& REIS, T. B. Satisfação dos clientes: uma análise da qualidade dos serviços prestados por um hospital do norte fluminense. Perspectivas Online, v. 5, n. 14, 2015.

PINTO, R. S. \& FONTENELLE, M. A. M. Desdobramento da Função Qualidade - QFD no processo de desenvolvimento de produtos: Uma aplicação prática. In: XXXIII ENEGEP, Salvador, 2013.

PRASZKIEWICZ, I. K. Application of neural network in QFD matrix. Journal of Intelligent Manufacturing, V. 24, p. 397-404, 2013.

SCHELlER, A. \& MIGUEL, P. A. C. Aplicação do Método QFD na Proposição de Nova Matriz Curricular para um Curso de Graduação de uma Universidade Pública do Sul do Brasil. Revista de Ensino de Engenharia, v. 31, n. 2, p. 1-16, 2012.

SINAPROCIM - Sindicato Nacional da Indústria de Produtos de Cimento. Dados Setoriais 2013: Faturamento Nacional do Setor. 2014. Disponível em: <http://sinaprocim.org.br/portal/wpcontent/uploads/2015/04/faturamento-2013.pdf>. Acesso em: $11 \mathrm{dez} .2015$.

UNTERLEIDER, C. \& SELLITTO, M. Aplicação do QFD em etapas iniciais do desenvolvimento de um odorizador de automóveis. Revista Produção Online, v. 12, p. 377-401, 2012.

YIN, R. K. Estudo de caso: planejamento e métodos. 5. ed. Porto Alegre: Bookman, 2015. 